\title{
中国西部地区地表植被覆盖和积雪覆盖变化 对沙尘天气的影响
}

\author{
徐兴奎 陈 红 \\ (中国科学院大气物理研究所国际气候与环境科学中心, 北京 100029. E-mail: xkxu@mail.iap.ac.cn)
}

\begin{abstract}
摘要 自然正交 $(\mathrm{EOF})$ 分解生成的 $80 \mathrm{~km} \times 80 \mathrm{~km}$ 归一化植被指数(NDVI)显示, 自 1982 1994 年间中国西 部区域地表植被覆盖率呈增加趋势, 1995 年前后, 地表覆盖状况有下降趋势, 地表覆盖变化存在很大的 空间差异. 其中第一、二特征向量时间系数可以很好地反映中国西部区域局地植被覆盖率的年变化. 通 过 NDVI 与西部区域沙尘暴、扬沙、浮尘年发生频次相关分析得出, 地表植被的年变化是影响沙尘等灾 害性天气发生的最主要地表特征因素. 同时, 相关分析显示, 在西部部分地区, 降雪量也是影响沙尘天 气的重要地表特征因子. 采用遥感数据、气象观测数据, 通过数理分析方法, 直接证明了中国西部地区 地表植被、积雪覆盖变化对沙尘天气发生频次的影响.
\end{abstract}

关键词 沙尘天气 植被覆盖 积雪

气候系统对自然的或人为因素诱发的地表特征 变化极为敏感 1 1 13]. 如地表覆盖类型的时空变化, 可 引起地表物理性质的非均匀分布, 从而导致地表能 量分配和转换机制不同, 直接影响区域气候环境的 形成和变化 ${ }^{[14 ~ 16]}$. 研究显示, 引起下垫面覆盖类型变 化的因素包括自然的和非自然因素, 无论哪种因素 引起的地表特征改变, 都会对区域气候温湿分布造 成显著的影响 ${ }^{[17 \sim 19]}$. 同时, 地表覆盖类型时空分布的 多样性和多变性, 也会造成地表物理参数的复杂分 布, 并直接影响大气环流的发展和变化 ${ }^{[20]}$. 作为陆面 过程的一个特殊群体, 干旱和半干旱地区植被覆盖 率极低, 很高的反照率和气温使感热大大高于潜热, 直接影响到该区域的降水 ${ }^{[21 ~ 24]}$, 降水的减少又使该 地区生态环境进一步恶化, 最终导致沙尘暴等灾害 性天气频繁爆发.

气候要素和地表物理特征是触发沙尘等灾害性 天气的两个必要因素 ${ }^{[25,26]}$, 同时两者又相互作用、相 互影响. 长期的气候适应以及气候差异造成了地表 特征的不均匀性分布, 而这种不均匀性又会对局地 气候产生反馈作用. 气候因素为沙尘天气的发生提 供了动力条件, 持久的风力、足够强的天气系统为沙 尘天气提供了起沙和传输动力. 地表物理特性则为 沙尘天气的发生提供了必要的物理条件, 并极具脆 弱性. 气候系统的不确定性, 人为影响都会改变地表 特征的物理性质. 当两者超过某一阈值时, 沙尘天气 就可能发生.
中国西部地区地处干旱和半干旱地区, 地表覆 盖类型相对比较单一. 地表覆盖类型以沙漠和半沙 漠为主, 地表水资源有限, 植被生长所需水的主要来 源是自然降水, 降水的多少直接影响地表覆盖密度. 春季积雪融化蒸发、地表干燥, 无植被覆盖; 夏秋季 节, 少量的降水使地表植被覆盖率增加; 冬季, 降雪 覆盖了西部大部分区域, 其地表物理属性年变化很 大. 与此对应, 中国西部地区灾害性天气也呈规律性 变化. 春季沙尘天气频发, 夏秋冬季逐渐减少 27$]$, 这 种变化特征暗示沙尘天气与地表特征变化之间存在 相关联系. 研究显示, 沙尘天气具有年际变化特征, 从 80 年代初至 1997 年间, 中国西部区域沙尘天气出 现频次呈逐年下降趋势, 1997 年后开始呈上升趋势 [28]. 动力分析表明, 风速的年变化与沙尘天气的发生 频次高度相关 ${ }^{[29]}$. 但作为影响沙尘天气重要因素的 地表特征究竟起到什么作用, 这方面的研究甚少. 虽 然有些研究认为沙尘天气的发生与地表植被覆盖率 减少有关 ${ }^{[30]}$, 但已有的研究都没有对西部区域地表 覆盖特征的时空变化特征作出分析, 并在时空尺度 上对地表特征变化与沙尘的关系作出令人信服的验 证. 因此, 本文通过利用 1982 2000 年 NOAAAVHRR遥感数据和 1970 2000 年 616 气象台站观 测数据, 在时空尺度上分析地表植被覆盖率年变化、 降雪年变化与沙尘天气发生频次的关系, 通过数 理分析直接证实地表特征变化对沙尘天气发生的 影响. 


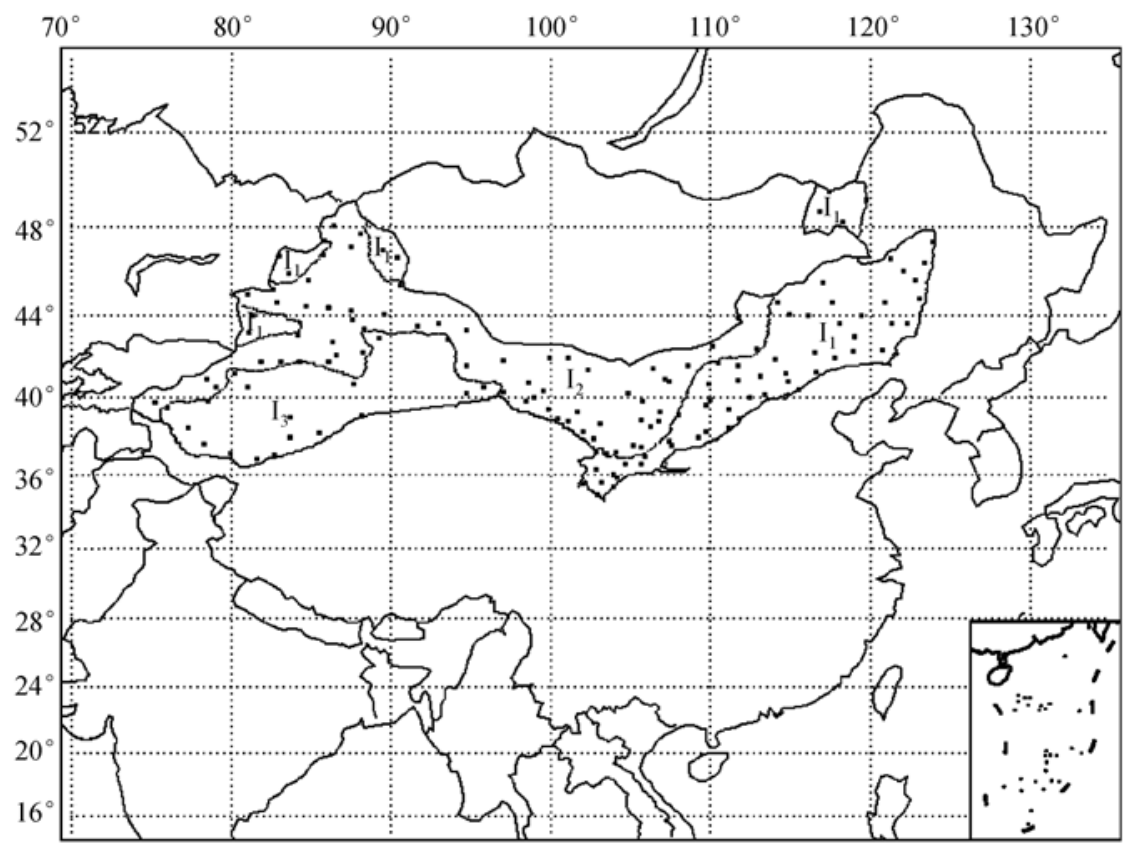

图 1 三个气候区域的分布以及气象台站分布

\section{1 研究区域}

图 1 所示为本文所研究的中国西部地区三个气候 区域，包括: 中温带亚干旱大区 $\left(l_{1}\right)$ 、中温带干旱大区 $\left(I_{2}\right)$ 、南温带干旱大区 $\left(I_{3}\right)$, 以及气象台站在三个区域 的分布. 本文之所以选定这样的中国西部地区的划定, 是出于以下 4 种考虑: 第 1 , 在地理分布上, 该区域位 于中国的西部地区; 第 2, 受气象观测台站的限制, 本 文选取中国西部部分地区. 因为在中国西部地区，气 象观测台站有限, 如位于西南部的青藏高原, 气象台 站很少, 如果选取这些地区, 最终结果可能存在很大 的误差. 第 3, 中国南北横跨几个不同气候带, 受气候 的影响, 地表植被的生长期差别很大. 对于自然植被 而言, 气候条件决定了他们的生长周期, 而对于农业 作物, 受人类影响, 因所处的气候区域不同, 复种指 数存在较大的差异. 因此, 我们采用中国气象局绘制 的气候区划定义所研究的西部区域. 气候区划的标准 是: 这些区域的年降水量和年积温相似. 第 4 , 在研究 区域, 包含了近年来对中国环境影响较大, 争议也较 大的区域，同时也是沙尘天气频繁发生的区域.

\section{2 观测数据分析}

\subsection{NDVI 时空变化}

NDVI 是根据 NOAA-AVHRR 数据第 $1(0.58$
$0.68 \mu \mathrm{m})$ 和第 $2(0.725 \sim 1.10 \mu \mathrm{m})$ 信道反射特性差异来 反映下垫面覆盖和植被的动态变化信息, NDVI 越大, 说明地表植被覆盖状况越好. 它不仅包含了自然因 素对地表覆盖类型的影响, 而且也包含了人类活动 信息. 本文使用的 NOAA-AVHRR 数据来源于 NASA 提供的 $8 \mathrm{~km} \times 8 \mathrm{~km}$ 分辨率旬最大 NDVI 资料, 数据 经过了大气订正和角度订正, 消除了大气等因素的 影响, 使 NDVI 在空间尺度上具有可对比性.

为了使NDVI更加准确地反映出西部地区植被的 年变化趋势, 本文选取 5 10 月的平均NDVI代表年平 均NDVI. 理由在于: ( i ) 中国西部地区植被类型基 本是一年一生植被, 植被的生长周期与气温降水的 变化周期同步，5 10 月份是地表植被覆盖密集时期， 而且 5 月份与 10 月份NDVI振幅基本相同(图 2); (ii) 可以消除非植被生长季节地表特征变化对NDVI的影 响. 为了更加准确地进行时空分析, 通过平均计算, 将NDVI分辨率降为 $80 \mathrm{~km} \times 80 \mathrm{~km}$, 这样做一方面使 NDVI时间序列变得更加平稳; 另一方面减少空间点 阵, 使之更加适合EOF数学分析. NDVI的平均处理并 不会掩盖区域内自然植被和农业植被NDVI的变化趋 势, 首先各种植被在生长季节NDVI变化趋势基本相 似; 其次西部地区裸露土壤湿度极低, 裸土的NDVI 月际变化比较平稳 ${ }^{[31]}$; 再则NDVI是每旬最大NDVI,

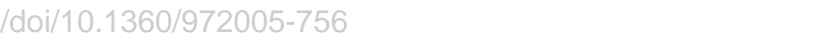


定因素对 NDVI 的影响.

EOF 分析即经验正交函数分析. 基本原理是将 时间尺度为 $t$ 的 $n$ 个空间场 $F(t, n)$ 分解成为由时间权 重矩阵 $T$ 和空间特征向量 $X$ 的乘积:

$$
F_{i j}=\sum_{k=1}^{n} T_{i k} X_{k j},
$$

即, 时间序列场 $F(t, n)$ 可以由几个典型的空间特征场 和对应的时间权重来近似描述. 通过分析空间特征 场和对应的时间权重, 可以清楚 $F(t, n)$ 的时空变化特 征. 当时间序列稳定时, 第一特征值反映出时间序列 的变化趋势, 其他特征值可以反映出时间序列的局 地波动特征. 通过 EOF 方法对中国西部地区 1982 2000 年共 18 年平均 NDVI 距平分析(1994 年由于 NOAA 卫星问题, 没有数据), 从列出的 11 个特征向 量所占权重和累计权重来看, 前两个特征向量占总 方差的 59\%, 其中第一特征向量占总方差的 47\%, 远 较其他特征向量所占的比重大, 这表明对 NDVI 进行 EOF 分析结果比较理想(表 1).

(i ) 第一特征向量 第一特征向量场分布反映 所有研究区域的总体NDVI距平变化特征. 图 3 为 NDVI的第一特征向量场分布, 由图可见全区第一特 征向量场全部为正值, 表明NDVI距平变化具有明显 的空间一致性，第一特征向量大值中心几乎全部分 布在 I 1 区域. 由于时间系数的年际变化代表要素场分 布型的年际变化，因此可以根据时间系数的大小判
断 NDVI 距平的年际波动特征. 从 1982 1993 年间, 第一特征场时间系数波动比较明显, 但总体变化趋 势是逐渐增加的, 自 1993(或 1994 年)年之后开始呈 下降趋势(图 4). 这表明, 1982 1993 年间, 研究区域 植被覆盖状况总体上是在增加, 1993(或 1994 年)之后 植被覆盖状况呈退化趋势. 同时, 1987 年以前基本为 负值(1984 年除外), 说明全区 NDVI 一致偏低; 1988 年以后基本为正值(2000 年除外), 说明 1988 年后全 区 NDVI 一致偏高. 其中, 有几个峰值, 1984, 1988, 1990 和 1993 这几年为全区 NDVI 偏高的峰值年, 1982, 1986 和 2000 年为 NDVI 的低谷年.

(ii)第二特征向量 第二特征向量反映了NDVI 距平的区域变化特征. 第二特征向量场空间分布显 示(图 5), 在 $I_{1}$ 的南部和 $I_{2}$ 的西部, 第二特征场是正 值区域. $I_{1}$ 和 $I_{2}$ 的东部区域和 $I_{3}$ 区域为负, 这表明在 中国西部区域局地植被覆盖有两种反向变化过程, 有的区域植被覆盖得到改善, 有的区域植被在不断 退化. 第二特征场时间系数年变化能够反映出局地 植被覆盖状况的时间变化过程. 如图 6 所示, 1982 1993 年间第二特征场时间系数为负, 1993 年后时间 系数变为正值, 但总的趋势是一直在增加. 这种变化 趋势说明, I 1 的南部和 $I_{2}$ 的西部的第二特征场正值 区域，地表覆盖状况自 1982 2000 年间一直呈现增加 趋势; 而在 $I_{1}$ 和 $I_{2}$ 的东部和 $I_{3}$ 负值区域, 自 1993(后 1994 年)年始, 地表覆盖状况趋于恶化.

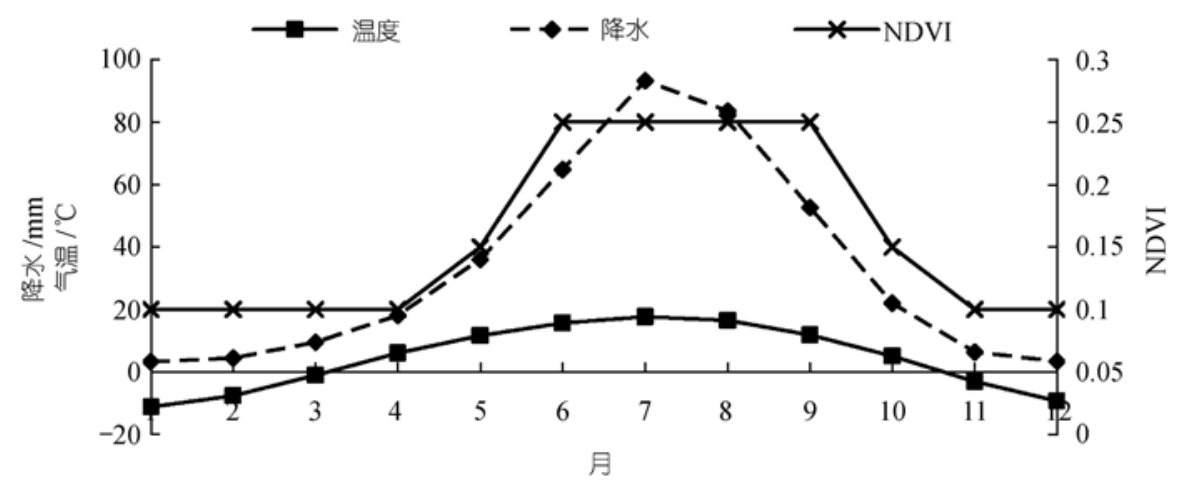

图 2 西部地区月降水量、月平均气温、月最大 NDVI 变化

表 1 特征向量占总方差的百分比

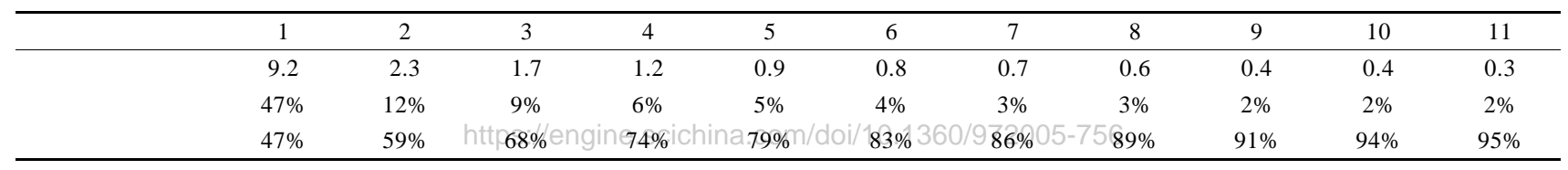




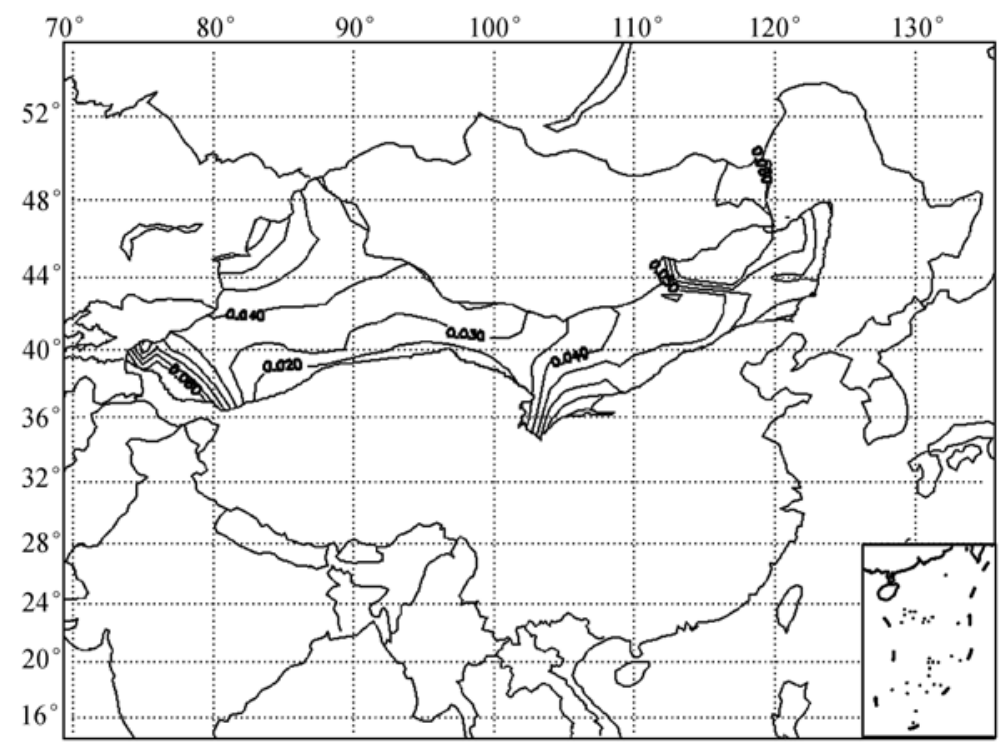

图 3 NDVI 第一特征向量场

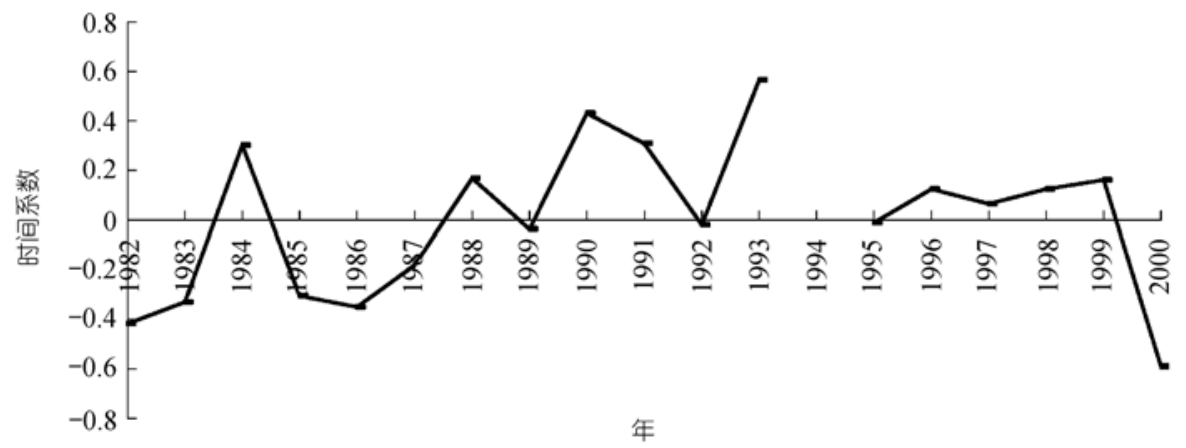

图 4 第一特征场时间系数

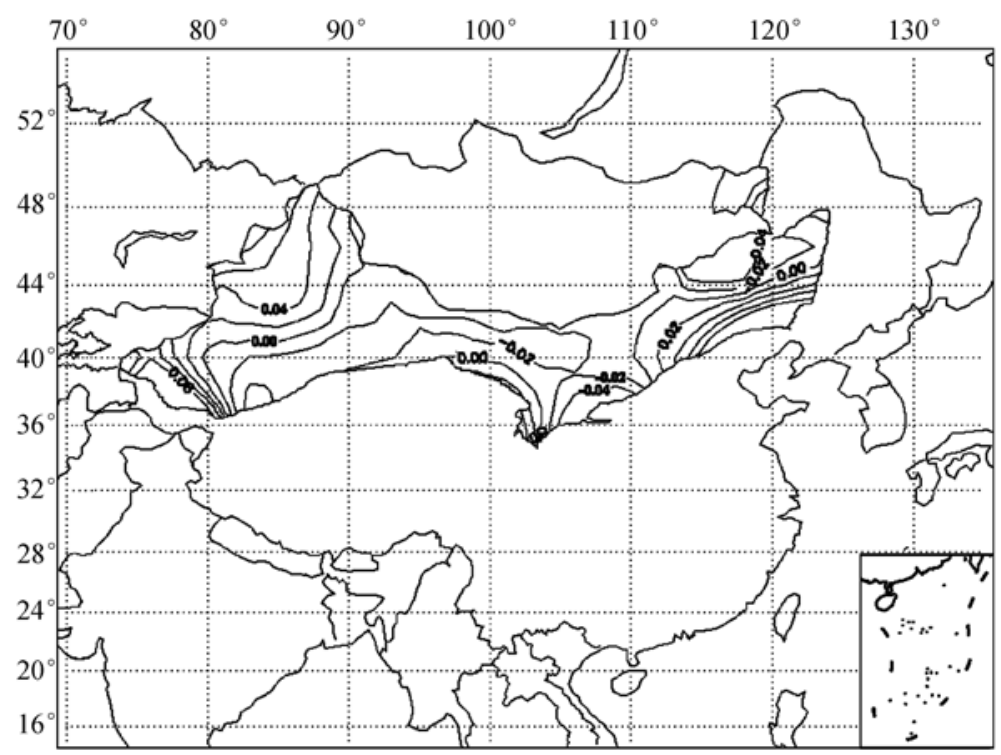

图 5 CicNDVI第二特征向量场972005-756 


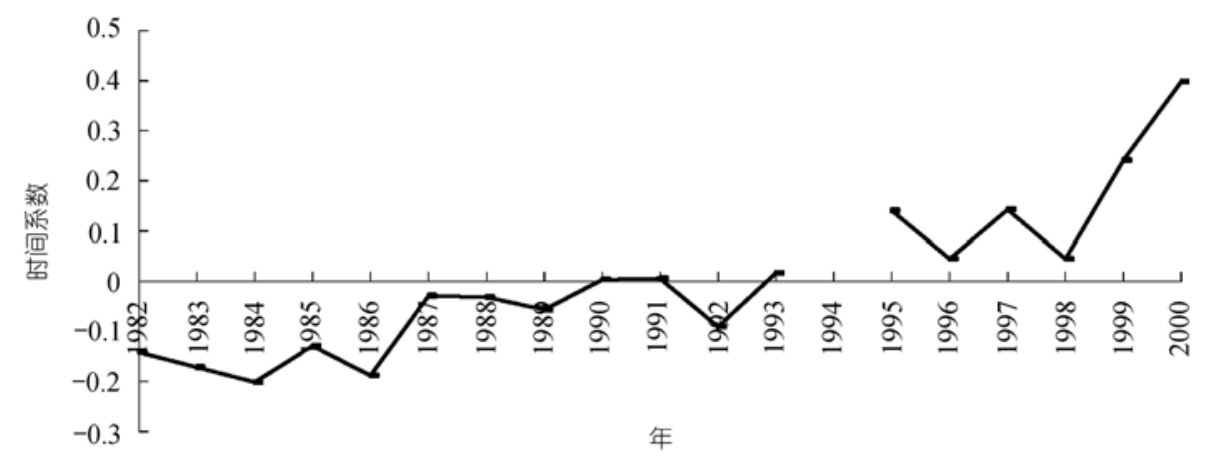

图 6 第二特征场时间系数

\section{2 沙尘发生频次与年降雪时空变化}

中温带亚干旱大区 $\left(I_{1}\right)$ 、中温带干旱大区 $\left(I_{2}\right)$ 、南 温带干旱大区 $\left(I_{3}\right)$ 是中国西部地区沙尘天气主要爆发地. 在中温带亚干旱大区(图 7(a))和中温带干旱大区(图 7(b)), 从 1970 1973 年期间, 沙尘暴、扬尘和起沙年 总频次呈增加趋势, 1974 1996 年期间开始下降, 但 1997 年始沙尘天气又开始增加. 在南温带干旱大区 $\left(I_{3}\right)$, 从 1970 2000 沙尘天气总体下降趋势(图 7(c)). 与各自区域沙尘变化趋势对应, 各区域年降雪量呈 现反向变化规律(图 8). 其中, 根据沙尘天气发生次 数的月际变化规律, 我们定义为

沙尘发生频次: 前年 8 月至当年 7 月各自区域观 测到的沙尘天气年总次数除以区域台站数.

从气候学角度, 定义为

年降雪量: 前年 8 月至当年 7 月各自区域观测到 的年降雪总量除以区域台站数.

3 地表特征变化对沙尘天气发生频次影响 的直接证据

地表植被覆盖及其年变化具有局地特征, EOF分 解的第一特征时间系数虽然能够代表NDVI的年变化 趋势, 但却是三个区域的总体变化趋势, 而第二特征 向量时间系数却能够很好地反映局地植被覆盖状况 的年变化趋势. 第二特征向量及时间系数也显示, 植 被退化相对严重的区域, 正是中国西部沙尘天气发 生频率最高的区域. 考虑到植被变化的区域特征以 及沙尘天气发生频次相对植被覆盖变化的滞后性, 本文分别用各自区域 5 10 月份平均NDVI与下一年 沙尘天气发生频次计算相关性(表 2). 结果显示, 在 $\mathrm{I}_{1}$ 和 $\mathrm{I}_{2}$ 这两个研究区域, NDVI与沙尘暴、扬沙和浮 尘的相关系数绝对值全部大于 0.468 , 相关性明显, 超过了 0.05 的显著性检验水平. 这说明, 地表植被覆
盖的年变化是造成上述两个地区沙尘暴、扬沙和浮尘 发生频次年波动的重要因素之一. 影响的机理在于 植被的根茎和腐殖质对地表沙粒有固定作用. 在 I 3 区 域, 相关并不显著, 原因在于 $1_{3}$ 绝大部分区域地表类 型为沙漠, 植被覆盖的任何波动都难以改变 $I_{3}$ 区域 的总体地表特征.

在冬季, 中国西部区域降雪以固态形式覆盖在 地表, 春季溶化后, 增加土壤湿度, 这一过程可以抑 制或减少沙尘天气的发生. 计算沙尘暴、扬沙、浮尘 与年降雪量的相关系数, 结果显示(表 3), 在 I 1 区域, 除沙尘暴外, 降雪量与扬沙和浮尘的相关性明显, 相 关系数绝对值大于 0.355 , 通过了 0.05 的显著性检验 水平. 在 $\mathrm{I}_{1}$ 区域降雪与沙尘暴发生频次不显著的原 因有多种: ( i ) 这个区域不是沙尘暴的源区, 观测到 的沙尘暴天气可能来自其他区域; ( ii ) 在 I 1 区域, 因 为植被覆盖面积相对较大, 动力因素, 如风可能起更 大的作用; (iii) 与土壤质地有关(图 9). 在 I 1 区域, 土 壤质地以沙土和壤土为主, 壤土土壤颗粒间较大的 粘附力和相对较大的持水性, 是造成植被与大气要 素相互作用分布不均的重要因素之一 ${ }^{[32]}$, 也不利于 沙尘天气的发生. 在 $I_{2}$ 区域, 所有的相关系数都显著, 说明在 $I_{2}$ 区域降雪量是影响沙尘天气发生的重要因 素之一. 这一方面与 $I_{2}$ 区域是中国西部沙尘天气主 要爆发区有关, 另一方面与土壤质地大多是沙土有 关. 而在 $I_{3}$ 区域相关性不显著, 这与 $I_{3}$ 区域地处中 国最干旱区域, 年降雪量少有关.

\section{4 结论和讨论}

造成沙尘天气发生频次波动的因素有很多. 除 本文涉及的植被和积雪覆盖外, 土壤温湿、环流形 势、降水、地形等地面条件都会影响沙尘天气的发生, 但本文只选择了地表植被覆盖(NDVI)和积雪两个地 

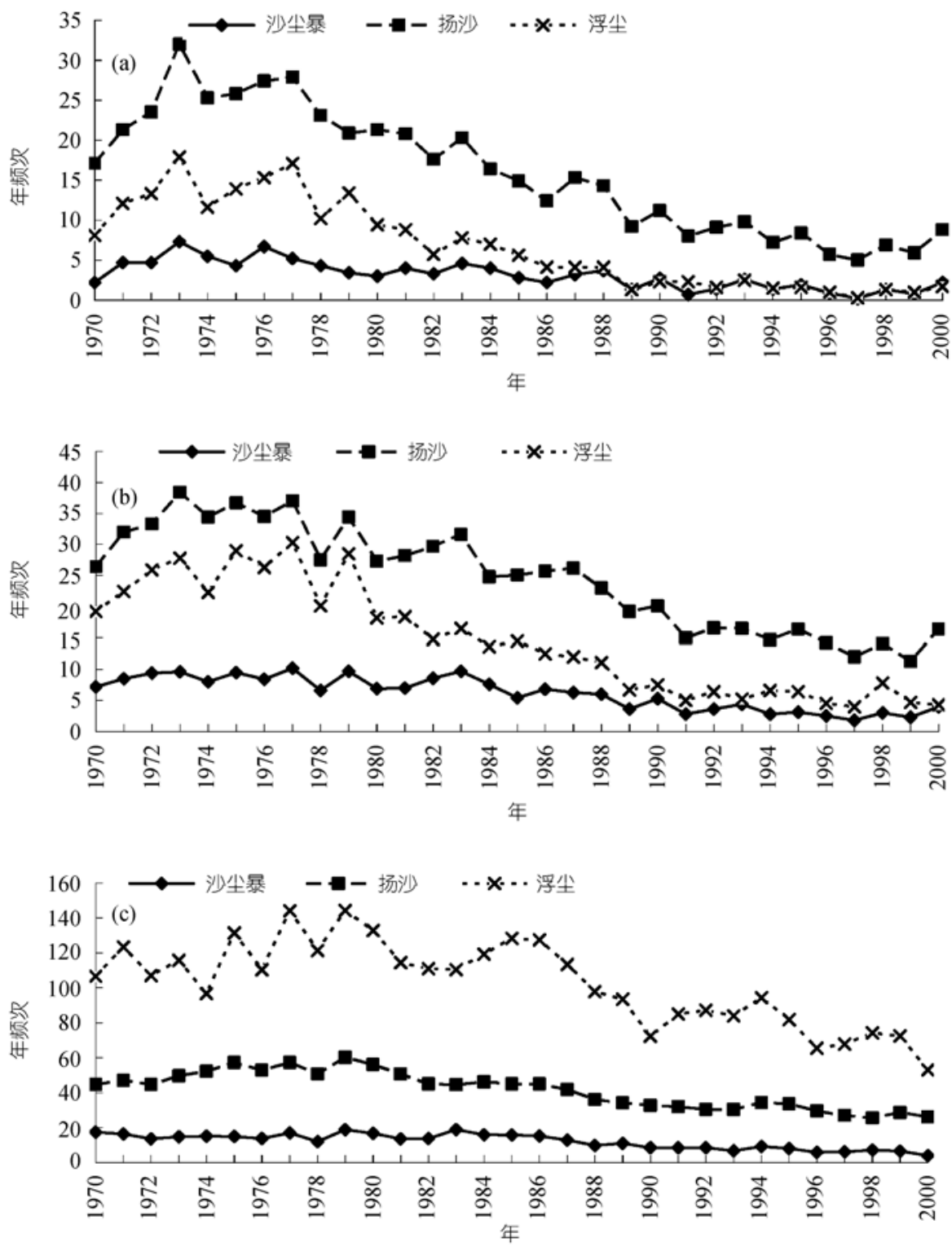

图 7 沙尘暴、扬沙、浮尘在三个区域的分布((a) $I_{1}$, (b) $I_{2}$, (c) $I_{3}$ )

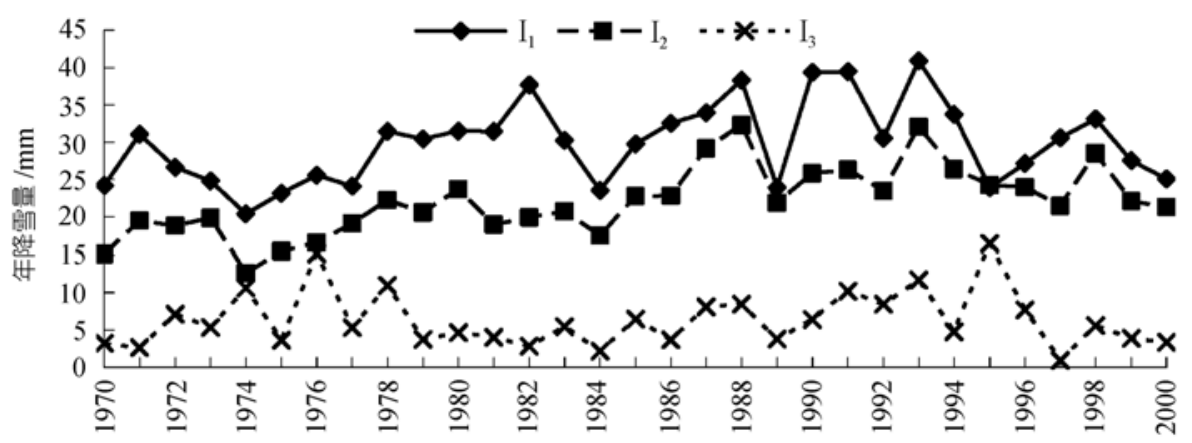

图 8 各自气候区域年降雪量年际变化 
表 2 沙尘暴、扬沙、浮尘与 NDVI 的相关系数

\begin{tabular}{lccc}
\hline & 沙尘暴 & 扬沙 & 浮尘 \\
\hline 中温带亚干旱大区 $\left(I_{1}\right)$ & -0.70 & -0.64 & -0.62 \\
中温带干旱大区 $\left(I_{2}\right)$ & -0.74 & -0.66 & -0.60 \\
南温带干旱大区 $\left(I_{3}\right)$ & -0.34 & -0.34 & -0.20 \\
\hline
\end{tabular}

表 3 沙尘暴、扬沙、浮尘与年降雪量的相关系数

\begin{tabular}{lccc}
\hline & 沙尘暴 & 扬沙 & 浮尘 \\
\hline 中温带亚干旱大区 $\left(I_{1}\right)$ & -0.31 & -0.36 & -0.41 \\
中温带干早大区 $\left(I_{2}\right)$ & -0.55 & -0.59 & -0.62 \\
南温带干早大区 $\left(I_{3}\right)$ & -0.22 & -0.06 & -0.16 \\
\hline
\end{tabular}

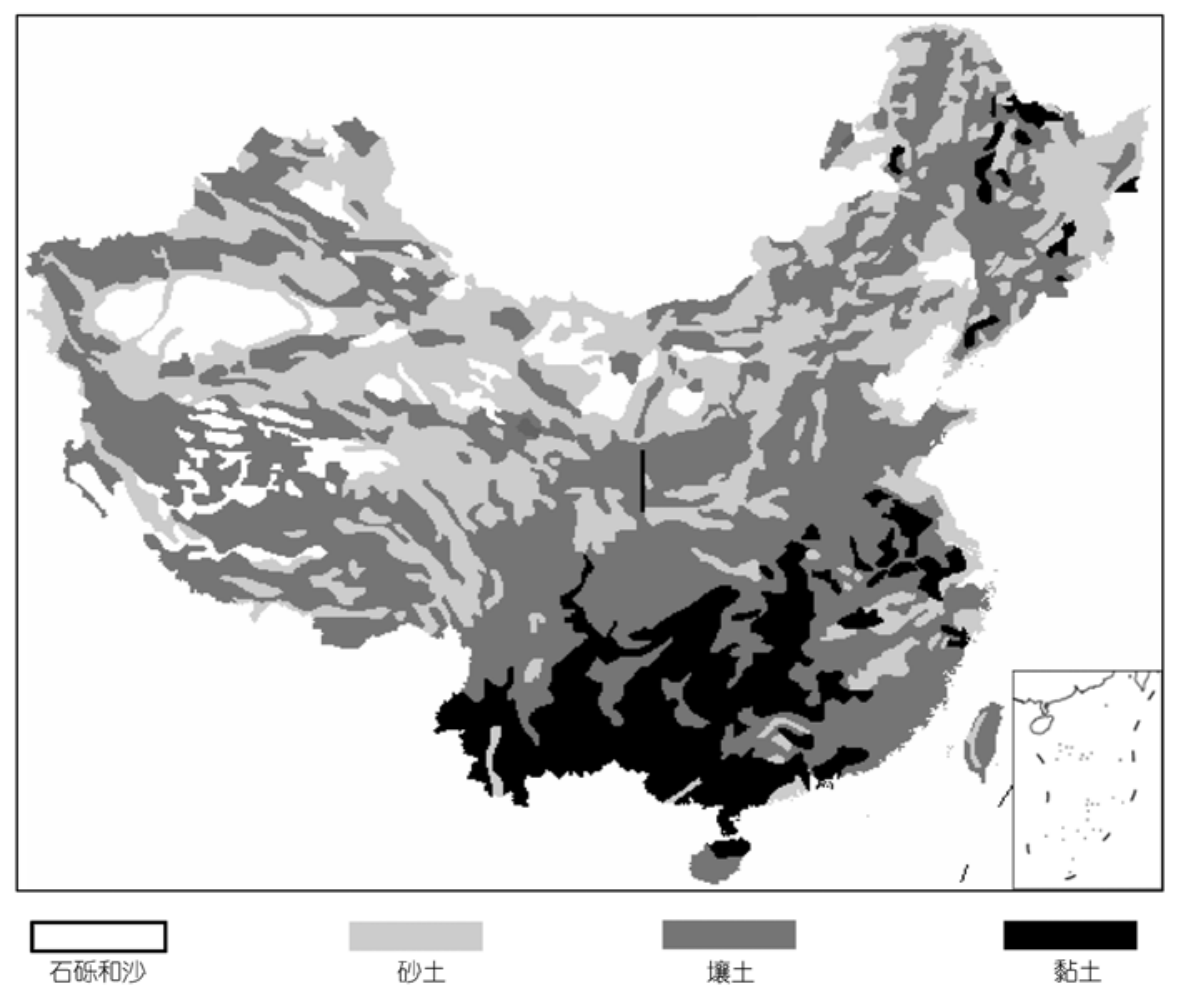

图 9 土壤质地分布

表特征因子作为研究对象, 主要原因是由于这些影 响因素中有部分是相互关联的: ( i ) 在西部地表植 被生长区域, 下垫面覆盖类型变化会影响区域温湿 分布, 而适合的降水、温湿分布又利于植被生长, 因 此NDVI本身是地表和气候综合特征的体现, 其中也 包含了人为因素对地表环境的影响; 而在植被非生 长季节, 对地表特征和沙尘天气影响最大的因素是 地表积雪. (ii) 在西部无植被覆盖的区域, 冬季和春 季气温、积雪量是影响沙尘天气发生频次的最重要的 地表特征因素, 但在非积雪覆盖季节, 其他要素如温 度和降水等与沙尘发生频次之间关系并不是很明显 [25]. 这一方面是由于夏秋季节, 无植被区域降水少、 蒸发强烈, 这种短期微弱的地表湿度变化对沙尘天 气年变化频次的影响不大; 另一方面是因为其他区 域植被的存在, 改变了西部整体地表特征; 同时, 天
气系统的季节性特征对沙尘天气发生频次的季节性 分布也至关重要 ${ }^{[33]}$. 因此本文着重分析地表植被覆 盖和积雪两个主要的地表特征因子与沙尘天气年发 生频次间的关系, 并得出如下结论:

（i）气象因子和地表物理特征是影响中国西部 区域沙尘天气发生频次年变化的两个重要因素. 在 气象因子适合的条件下, 地表特征的物理性质决定 沙尘天气是否发生.

(ii) 地表植被覆盖率决定了沙尘天气年发生的 频次. 通过对中国西部三个区域的分析得出, 除植被 稀少的南温带干旱大区 $\left(I_{3}\right)$ 外, 在沙尘天气频发的区 域, 地表覆盖率年变化与沙尘天气年发生的频次高 度相关, 可以很好的解释中国西部地区沙尘天气年 波动规律, 也直接证明了中国西部区域地表植被改 善和退化, 都会对西部环境造成强烈的影响. 
(iii) 积雪也是影响沙尘天气年发生频次的重要 地表特征之一. 除降雪量较少的干旱区域 $I_{3}$ 外, 在其 他区域, 年降雪量与沙尘天气年发生的频次也具有 很好的相关性.

(iv) 通过本文研究结果, 可以得出, 在中温带 亚干旱大区 $\left(I_{1}\right)$ 、中温带干旱大区 $\left(I_{2}\right)$ 区域，人为地 对地表施加影响, 改善这两个区域的地表植被覆盖 状况, 可以有效抑制或减少沙尘等灾害性天气的发 生频次; 而对于南温带干旱大区 $\left(\mathrm{I}_{3}\right)$, 由于自然状况 限制, 通过人为活动改善区域环境的可能性很小.

致谢 本文受到财政部资助项目(Y0101)、中国科学院知识 创新方向性项目(批准号: KZCX3-SW-221)以及国家自然科 学基金重点项目(批准号: 40233027)联合资助.

\section{参考文献}

1 Baron J S, Hartman M D, Kittel T G F, et al. Effects of land cover, water redistribution, and temperature on ecosystem processes in the South Platte basin. Ecol Appl, 1998, 8: 1037 1051

2 Bonan G B. Effects of land use on the climate of the United States. Climatic Change, 1997, 37: 449 486[DOI]

3 Bounoua L, Collatz G J, Los S O, et al. Sensitivity of Climate to Changes in NDVI. Journal of Climate, 2000, 13: 2277 2292[DOI]

4 Charney J G, Quirk W J, Chow S H, et al. A comparative study of the effects of albedo change on drought in semi-arid regions. J Atmos Sci, 1977, 34: 1366 1385

5 Lauenroth W K, Burke I C, Gutmann M P. The structure and function of ecosystems in the central North American grassland region. Great Plains Res, 1999, 9: 223 259

6 Lewis $\mathrm{T}$. The effect of deforestation on grown surface temperatures. Global Planetary Change, 1998,18: 1 13[DOI]

7 Ning Zeng, Neelin J D, Lau K M, et al. Enhancement of interdecadal climate variability in the Sahel by vegetation interaction. Science, 1999, 286: 1537 1540[DOI]

8 Pielke R A. Overlooked issues in the U.S. National Climate and IPCC assessments. Preprints, 11th Symposium on Global Change Studies, 80th AMS Annual Meeting, Long Beach CA, January 9-14, 2000, 32 35

9 Pitman A, Pielke R, Avissar S R, et al. The role of the land surface in weather and climate: does the land surface matter? IGBP Newsletter, 1999, 39: 4 9

10 Shukla J. Predictability of time averages. Part II: The influence of the boundary forcing. Problems and Prospects in Long and Medium Range Weather Forecasting. In: Burridge D M, Kallen E, eds. London: Springer-Verlag, 1984, 155 206

11 Skinner W R, Majorowicz J A. Regional climatic warming and associated twentieth century land-cover changes in north-western North America. Climate Res, 1999, 12: 39 52
12 Wang G, Eltahir E A B. Ecosystem dynamics and the Sahel drought. Geophys Res Lett, 2000, 27: 795 798[DOI]

13 Wang G, Eltahir E A B. Role of vegetation in enhancing the low-frequency variability of the Sahel rainfall. Water Resources Res, 2000, 36: 1013 1021[DOI]

14 张耀存, 钱永甫. 陆地下垫面特征对区域能量平衡过程影响的 数值试验. 高原气象, 1995, 14(3): 325 333

15 周锁铨, 陈万隆. 青藏高原植被下垫面对东亚大气环流影响的 数值试验. 南京气象学院学报, 1995, 18(4): 536 542

16 周锁铨, 陈万隆, 王革丽. 夏季中国高原植被气候效应的数值 研究 I: 模式及降水、流场的效应. 南京气象学院学报, 1997, 20(2): 158 163

17 罗哲贤. 植被带宽度对局地环流及温度场影响的数值研究. 地理 学报, 1994, 19(1): 37 45

18 刘树华, 黄子琛, 刘立超. 半干旱区植被覆盖度对边界层气候热 力影响的数值模拟. 气象学报, 1996, 54(3): 303 311

19 郑益群, 钱永甫, 苗曼倩. 植被变化对中国区域气候的影响 I 一初步模拟结果; II 一一机理分析. 气象学报, 2002, 60(1): 1 29

20 Charney J G. Dynamics of deserts and droughts in the Sahel. Quarterly Journal of the Royal Meteorological Society, 1975, 101: 193 202

21 Balling R C. The climatic impact of a Sonoran vegetation discontinuity. Climatic Change, 1988, 13: 99 109

22 Balling R C. Impact of desertification on regional and global warming. Bulletin of the American Meteorological Society, 1989, 72: 232 234

23 Gee G W, Wierenga P J, Andraski B J, et al. Variations in water balance and recharge potential at three western desert sites. Soil Science Society of America Journal, 1994, 58: 63 72

24 Schlesinger W H, Fonteyn P J, Marion G M. Soil moisture content and plant transpiration in the Chihuahuan Desert of New Mexico. Journal of Arid Environments, 1987, 12: 119 126

25 赵景波, 杜娟, 黄春长. 沙尘暴发生的条件和影响因素. 干旱区 研究, 2002, 19(1): 58 62

26 石广玉, 赵思雄. 沙尘暴研究中的若干科学问题. 大气科学, 2003, 27(4): 591 606

27 潘耀忠, 范一大, 史培军, 等. 近 50 年来中国沙尘暴空间分异 格局及季相分布一一初步研究. 自然灾害学报, 2003, 12(1): 1 8

28 钱正安, 宋敏红, 李万元. 近 50 年来中国北方沙尘暴的分布及 变化趋势分析. 中国沙漠, 2002, 22(2):106 111

29 王小玲, 翟盘茂. 中国春季沙尘天气频率变化及其与地面风场 和气压场的关系. 气象学报, 2004, 62(1): 96 103

30 Zou X K, Zhai P M. Relationship between vegetation coverage and spring dust storms over northern China. J Geophys Res, 109, D03104, doi: 10.1029/2003JD003913, 2004[DOI]

31 童庆禧. 中国典型地物波谱及其特征分析. 北京: 科学出版社, 1990

32 徐兴奎, 林朝晖, 薛峰, 等. 气象因子与地表植被生长相关性分 析. 生态学报, 2003, 23(2): 221 230

33 张高英, 赵思雄, 孙建华. 近年来强沙尘暴天气气候特征的分 析研究. 气候与环境研究, 2004, 9(1): 101 115

(2005-06-29 收稿, 2005-10-12 接受) 